\title{
CARLOS LUIS FALLAS: VISION DE CONJUNTO
}

\author{
POR \\ MANUEL PICADO \\ Universidad de Costa Rica
}

La figura de Carlos Luis Fallas evoca de inmediato la multiplicidad de sus caminos y tareas a la vez que la constancia de sus luchas y posiciones.

Nacido en Alajuela en 1909, Fallas es testigo obligado de acontecimientos decisivos de la historia nacional y mundial. Sin embargo, tal como ya en 1933 lo había advertido Carmen Lyra ${ }^{1}$, Fallas no se limita al puesto del espectador contemplativo. En efecto, durante casi cuatro décadas es actor destacado en los más diversos papeles de la escena social: líder campesino y obrero, político respetado por seguidores y enemigos, escritor de difusión mundial, jefe militar por circunstancias, son algunas facetas de su fectunda vida.

A los veintidós años ya tiene seis de experiencia en el litoral atlántico de Costa Rica. Ahí ejerce variados oficios y conoce en carne propia las condiciones laborales de la United Fruit Company. En relación muy estrecha con los avatares de esta época, en julio de 1931 ingresa en el recién fundado Partido Comunista, organización de la cual se convertiría en eje primordial y en la que se mantuvo hasta su muerte, acaecida en 1966.

En las primeras décadas de este siglo habían surgido en el país los primeros intentos de organización popular, y estos movimientos afectarán decisivamente nuestra vida social. Ellos conducen, por ejemplo, a la fun-

\footnotetext{
${ }^{1}$ Refiriéndose a las primeras intervenciones políticas del escritor, dice Carmen Lyra a un periodista: «Viera usted qué fuerte es en historia Carlos Luis Fallas. Eso sí, no se ha limitado a contemplarla como mero espectador» (Trabajo, 12-XI-1933, p. 2).
} 
dación de un partido político que, inspirado, entre otras cosas, por la Revolución rusa de 1917, se propone una transformación radical de la sociedad costarricense. Así, en virtud de sus inquietudes políticas, Carlos Luis Fallas se reúne con una generación nueva, que ha hecho ya sus primeras experiencias encaminadas a una interpretación diferente de las características económicas, sociales y políticas del país. A partir de su ingreso en la actividad partidista, Fallas encuentra el estímulo cordial de Carmen Lyra, su mentora en el campo de las letras, y la amistad definidora de Luisa González, Manuel Mora, Jaime Cerdas y tantos otros con los que haría el camino de su vida.

Desde sus inicios en la actividad política, Carlos Luis Fallas exhibe un carisma indudable, y su propiedad verbal llama la atención. Sin embargo, no había realizado estudios formales avanzados. Cursó únicamente la escuela primaria y dos años de la secundaria. Su capacitación es, sobre todo, un esfuerzo por superarse, a fin de responder adecuadamente a las necesidades y presiones de su vida de militante. Esa práctica política es la que le enseña el grado en que comprender y transformar no son discernibles.

El gremio de los zapateros constituyó, para el escritor, el puente hacia su partido. El taller le resulta una escuela de dialéctica y de práctica de la argumentación. Al aprender el oficio de la zapatería, Fallas, lector incansable, ingresó también en uno de los círculos de trabajadores más preocupados por instruirse. Anécdotas de la época señalan que el interés de este gremio por educarse llega al punto de que los trabajadores que no sabían leer reunían dinero a fin de pagar un lector ${ }^{2}$. ( $\mathrm{H} H e r m o s o$ ideal del libro y la lectura, que de muchas formas contrasta con el panorama de hoy!)

Después de 1931, la biografía de Carlos Luis Fallas ya no puede separarse de la trayectoria de su partido y de la historia de Costa Rica. Es dentro de ese amplio proceso donde se inscribe su función pública y política: dirigente de la huelga bananera del Atlántico en 1934, regidor municipal en 1942, diputado al Congreso en 1944. Es también ahí donde él halla sentido para una producción literaria constitutiva del acervo costarricense y por la cual recibe el premio Nacional de Cultura correspondiente a 1965.

El 14 de noviembre de 1967 la Asamblea Legislativa declaró Benemérito de la Patria al escritor Carlos Luis Fallas.

2 Cfr. Marielos Aguilar Hernández, Carlos Luis Fallas y el partido comunista de Costa Rica (Tesis de licenciatura presentada a la Escuela de Historia de la Universidad de Costa Rica en 1981), p. 58. 
La vida de Fallas se liga de modo constitutivo a la agitación social y política que en los años cuarenta resume, en Costa Rica, la efervescencia de las décadas anteriores. Quienes, como el escritor, reciben por esas fechas el impacto de la historia, viven algunos eventos internacionales capaces de forjar una conciencia y de obligar a una toma de posición. Los contemporáneos de Fallas asisten a la crisis económica mundial del año 1929, viven la Guerra Civil española de 1936, contemplan el auge del nazismo y del fascismo y saben de la gestación de otra guerra mundial. Por otra parte, en el plano nacional, la huelga bananera de 1934 representa una grave denuncia de las condiciones de vida de miles de compatriotas y es otra muestra de los conflictos sociales que se acumulan por esa época. Es esta acumulación de contradicciones, de variada índole, la que precipita la crisis definitiva del modelo liberal de estado propio de la oligarquía cafetalera.

En estas coordenadas sociales, políticas y económicas se inserta un fenómeno cultural que marca rumbos inéditos al pensamiento costarricense. En efecto, las condiciones de posibilidad están dadas para que surja una promoción de escritores cuyo punto de arranque puede marcarse, en 1939, con la novela Vida y dolores de Juan Varela, publicada por un joven de escasos veinticinco años, Adolfo Herrera García (1914-1975).

La nueva generación de escritores no dispone de un acervo literario que muestre los rasgos de una tradición. Al inicio del siglo ha habido un grupo de autores que prácticamente inauguran la literatura costarricense, pero los del cuarenta se vinculan a ellos, sobre todo, en términos personales y efectivos. La nueva promoción de escritores no parece, entonces, reconocer un pasado literario, y, quizá por eso, en términos generales, no impugnan la labor de aquellos que los preceden. Desde un punto de vista amplio, puede afirmarse que el grupo de escritores del cuarenta no pretende un programa literario cabal, y su labor se plantea como derivación, más o menos inmediata, de sus respectivas experiencias vitales. La literatura tiende a representarse como testimonio y memoria.

No obstante, la coexistencia en este período de obras tan disímiles como Mamita Yunai y La ruta de su evasión, o Manglar y Ese que llaman pueblo, muestra el principio de un cuadro contradictorio. Bajo el rubro de Generación del 40 no deben borrarse las profundas diferencias que separan a las actitudes e intereses de los escritores y las magnitudes heterogéneas de sus textos.

Desde un punto de vista literario, la década del cuarenta puede verse 
a la luz de una pugna fundamental entre la ruptura y la repetición. En efecto, textos como los de Yolanda Oreamuno y Joaquín Gutiérrez introducen los primeros elementos de una crisis de la función narrativa, la cual, sumada a otros factores, renovó el género novelesco en Europa y, posteriormente, en América. No obstante, producciones como las de Fallas - Dobles consolidan, al mismo tiempo, las formas narrativas anteriores y las llevan a su mejor posibilidad.

Con lo anterior no se afirma que el intento de Fallas no pueda distinguirse del emprendido por García Monge a principios de siglo. Obviamente, las diferencias saltan a la vista. Sin embargo, la línea de sucesión priva sobre la posibilidad de algún corte. Por lo demás, un deslinde con pretensiones de ruptura no tiene mayor sentido dentro de los planteamientos que parecen sostener la práctica literaria de Fallas. En su caso, más que de una pretensión de escritura debe hablarse de una tarea política que toma, entre otros, el camino de lo literario. Para él, la literatura es fase, e incluso instrumento, de prácticas de otro orden.

Buena parte de los escritores del cuarenta aspiran a que la actividad literaria se vincule a sus posiciones en la cuestión social y a sus decisiones políticas. Sin embargo, no parecen advertir una especificidad, una dialéctica propia del plano ideológico y, en particular, del campo literario. Esto lleva a ignorar la existencia de ideologías de la literatura que preexisten a los textos y son capaces de determinar su producción y consumo. Del mismo modo, eso introduce tensiones y desfases entre el proyecto del autor y la circulación del texto en la red de representaciones de la vida social. En otras palabras: el escritor no se plantea la posibilidad de que su función literaria pueda quedar atrapada en marcos ajenos a su interés político e incluso contrarios a él.

\section{III}

En 1940, Carlos Luis Fallas inicia su carrera de narrador con la novela Mamita Yunai, la cual se daría a la publicadad al año siguiente. Gentes y gentecillas data de 1947, y, según diversas fuentes, esta segunda novela es la preferida del escritor. Marcos Ramírez (Aventuras de un muchacho) se publica en 1952, y en 1954 sale a la luz Mi madrina. La primera edición de esta novela se acompañó de dos relatos titulados Barreteros y El taller, respectivamente.

En 1968, en un volumen titulado Tres cuentos, la Editorial Costa Rica incluyó los dos últimos textos citados y dio a conocer «La dueña de la guitarra de las conchas de colores». Esta breve narración se considera un 
ejercicio literario de juventud $y$, de acuerdo con personas allegadas al escritor, merecía poco aprecio de su parte.

Mamita Yunai es el texto más conocido y comentado de Fallas. Se trata de un relato desprendido de su actividad política. La base de la novela está en el informe que el autor rindió ante su partido luego de haber sido fiscal de la mesa electoral en Talamanca durante las elecciones de 1940. La crónica de su labor fue publicada, por entregas semanales, en el periódico Trabajo, del 16 de marzo al 7 de septiembre de $1940^{3}$.

El tránsito del discurso periodístico al discurso literario no parece ser un fenómeno extraño en la década del cuarenta ni en fechas anteriores. Sería muy interesante establecer qué formas de considerar la cucstión literaria son las que permiten y autorizan el paso del periódico a la novela. En alguna medida, esas formas de concebir lo literario contribuirían también a explicar la suerte de Mamita Yunai en la fase nacional del concurso que la Editorial Farrar y Rinehart, de los Estados Unidos, auspició en 1940 con el fin de seleccionar la mejor novela latinoamericana ${ }^{4}$.

De acuerdo con Víctor Manuel Arroyo ${ }^{5}$, originalmente Fallas había escogido para su primera novela el título $A$ la sombra del banano, el cual se dejó sólo para la segunda parte del texto. Fue Carmen Lyra quien le sugirió la fuerza irónica del que hoy conocemos.

Desde el punto de vista temporal, Mamita Yunai exhibe una estructura muy particular. En un primer plano se cuenta la tarea del personaje Sibajita como fiscal del Bloque de Obreros y Campesinos en la mesa electoral de Amure, Talamanca. Este hilo narrativo permite conocer el carácter amañado del proceso electoral y muestra las deplorables condiciones de los indígenas de la región. Sin embargo, lo anterior es sólo un marco para el encuentro de Sibajita con el personaje Herminio, antiguo camarada de los bananales y a quien había perdido de vista hacía catorce años. Aquí la historia regresa a la época en que Sibajita, Herminio y Calero eran compañeros inseparables. Esta segunda instancia temporal, constituida por los recuerdos de Sibajita de su vida de bananero, constituye el grueso de la novela. En ella se ennarca el relato de la gran huelga bananera de 1934.

${ }^{3}$ La información fue obtenida en la tesis antes citada. Debe destacarse el valor documental de dicho trabajo.

4 Para mayor información sobre el asunto resulta muy útil el trabajo de Guillermo Castro Robles. Cfr. Análisis estilistico de "Mamita Yunai» (Tesis de licenciatura presentada a la Escuela de Filología, Linguística y Literatura de la Universidad de Costa Rica en 1975), pp. 213 y ss.

${ }^{3}$ Cfr. Carlos Luis Fallas (San José, Costa Rica: Publicaciones del Ministerio de Cultura, Juventud y Deportes, 1973), p. 43. 
El interés de Manita Yunai se centra en la mostración del espacio social y humano. Para eso, el narrador se entrega a una actividad intensa de percepción sensorial en que se imponen lo auditivo y visual. La tarea narrativa se acerca a la recolección de datos e impresiones de los sentidos y esto genera una verosimilitud caracterizada por la acumt1lación de los detalles.

En Mamita Yunai, el narrador se concibe como una conciencia organizadora que dispone de amplia información y desarrolla un juicio moral sobre el mundo que despliega. La función narrativa se entiende como crónica y testimonio, y el narrador desempeña un papel importante no sólo como personaje, sino también como mediador ante el lector. La posición de lectura está altamente saturada debido a que el modo de contar supedita al lector y lo inclina a una tarea de mera recepción. En otros términos: las relaciones del narrador y el lector son las propias, por ejemplo, del relato clásico del siglo xix. Por lo demás, ésas son, en general, las relaciones del narrador y el lector en la obra de Fallas. La información es exhaustiva, se apela explícitamente al receptor y se generan relaciones de confianza y seguridad. La función narrativa no está en crisis como, por ejemplo, en La ruta de su evasión ${ }^{6}$.

El título de la segunda novela de Fallas, Gentes y gentecillas, apunta a un universo de carácter maniqueo. Esto, por otra parte, resulta bastante frecuente en la novela de la década del cuarenta. Piénsese en el valor de 1a oposición hombre-mujer en la novela, antes citada, de Yolanda Oreamuno o en la distinción de personajes sí y personajes no que se da en Una burbuja en el limbo (1946), de Fabián Dobles.

De modo muy similar a Mamita Yunai, Gentes y gentecillas centra su interés en la mostración de un tejido de conflictos personales que se derivan de contradicciones sociales y las ilustran. El grupo de la gente lo encarna doña Rosita, personaje en quien se acumula todo tipo de valoraciones negativas. El grueso de las figuras está del lado de las «gentecillas» y se condensa en el personaje Jerónimo. El narrador, explícitamente, se inclina hacia el segundo grupo, y con el término peyorativo irozina una estructura de términos complementarios y la invierte.

La figura del personaje Jerónimo no sólo asegura un principio de unidad a los múltiples hilos narrativos. También proporciona un medio para emitir un juicio moral sobre las costumbres sociales: el racismo, la frivolidad, la seducción, el carácter venal de las autoridades y de los periodis-

- Desde el punto de vista del discurso literario es de gran interés la investigación de Alicia Miranda Hevia. Cfr. Rasgos del relato moderno en «Mamita Yunais (Tesis de licenciatura presentada a la Escuela de Filología, Lingüística y Literatura de la Universidad de Costa Rica en 1976). 
tas, etc. La crítica social es quizá más atenuada que en Mamita Yunai, 1o cual puede explicarse como una manera de destacar el final: nace la conciencia de la necesidad de organización popular.

Respecto de Mamita Yunai, en Gentes y gentecillas el trabajo narrativo de Fallas acentúa su carácter de regresión. En efecto, mientras que la historia primaria de Mamita Yunai se sitúa a muy corta distancia del momento de escritura, la segunda novela se ubica en 1928. Por otra parte, resulta interesante observar que esta línea regresiva se acentuará hasta terminar encontrando, con Marcos Ramirez, la infancia del escritor. El afán narrativo converge, así, con el de cierto tipo de historiador; se trata de cubrir, con el relato, la extensión del pretérito, de recuperarlo, también, si es del caso. Esta idea del relato como regresión creciente, que, al narrarla, agota la geografía del pasado, debe pensarse en relación con el abandono de la escritura observado en Fallas después de su novela autobiográfica.

La profusión de voces narradoras es un rasgo acusado en Gentes y gentecillas. Abundan las intervenciones narrativas de los personajes y destaca, en particular, la historia del Diluvio Universal contada por Jacinto Artavia. Esta es una verdadera pieza de folklore que se inserta, por ejemplo, en la línea de Uvieta, de Carmen Lyra, o de Cuentos de Tata Mundo (1955). En relación con esto, es importante anotar que en la narrativa de Fallas la veta costumbrista no se pierde. Sin embargo, de ninguna manera tiene lugar constitutivo en el relato ${ }^{7}$.

Marcos Ramirez puede considerarse novela de evolución o formación de personaje. El texto posee un narrador que cuenta sus propias aventuras infantiles, y esto plantea una situación, en alguna medida, paradójica: se narran las aventuras de un niño, pero desde la perspectiva de un adulto.

Las primeras páginas de la novela cuentan la existencia casi idílica de Marcos junto a su familia materna. Con ello se traza la historia de su estirpe, los Ramírez, y se otorga al personaje una filiación. Luego, con el ingreso a la escuela, comienzan los verdaderos líos de Marcos, y a partir de aquí, su vida será una trayectoria creciente de situaciones irregulares y riesgosas.

La infancia de Marcos es una cadena interminable de procesos narrativos altamente episódicos marcados por una falta casi total de éxito. La historia de Marcos, su larga cadena de tumbos y tropiezos, se resuelve, al

${ }^{7}$ Para el conocimiento de la segunda novela de Fallas desde un punto de vista literario resulta muy útil el trabajo de Lydia Luarca Saballos. Cfr. «Gentes y gentecillas», una novela moderna en la década del 40 (Tesis de licenciatura presentada a la Escuela de Filología, Linguística y Literatura de la Universidad de Costa Rica en 1977). 
final, en el anuncio de una aventura decisiva: un porvenir basado en las convicciones que se ha forjado en sus correrías a través de los libros. De esta manera, la novela cierra las aventuras del personaje y apunta hacia la figura del narrador.

A pesar de estar centrada en el personaje, Marcos Ramírez es una novela que no abandona las preocupaciones sociales de las otras obras del autor. Por el contrario, al ser novela de evolución del personaje se favorece la mostración del mundo social. Esto no puede ser de otra manera, puesto que sólo en contacto permanente con los otros puede verificarse la formación del personaje.

Resulta muy curioso constatar que ciertas actitudes adoptadas ante la novela en el ámbito nacional ya estaban prefiguradas e ironizadas en el texto mismo. Pareciera, pues, que, a pesar suyo, algunos lectores no han hecho otra cosa que dramatizar la novela. En efecto, hace algunos años era posible encontrar artículos periodísticos en los que se insistía en mantener a Marcos Ramírez fuera de los programas escolares y no faltaba quien señalara al personaje como un desadaptado que debía ser recluido en un reformatorio. La fórmula fácil de ciertos realismos («el texto es un espejo de la vida») resulta, entonces, completamente invertida ${ }^{8}$.

Al igual que en la novela antes comentada, en Mi madrina el personaje central es un niño. Asimismo, un espacio es común a ambas: Alajuela y sus alrededores. Por otra parte, la novela también puede considerarse de evolución o formación de personaje; en este caso, de Juan Ramón Artavia.

Destaca en Mi madrina una mentalidad providencialista. Esto se vincula al papel importante que para los acontecimientos juega el azar y la caridad. También puede apuntarse en Mi madrina una especie de estructura de consolación. De acuerdo con la dedicatoria de la novela, el texto se escribe justamente para señalar que los esfuerzos y previsiones de la madrina alcanzaron feliz realización; es decir, que el personaje Juan Ramón cumplió y que las cosas se concatenaron para que eso fuera posible.

Por su escenario y su temática, Barreteros se liga estrechamente a Mamita Yunai. El relato dramatiza los extremos de la explotación y la injusticia centrando las acciones alrededor de la muerte de un dinamitero. De acuerdo con el texto, trabajar significa entrar en un comercio directo y desigual con la muerte, debido a que el interés material se impone sobre el humano.

\& Para ilustrar esto véanse, por ejemplo, los dos artículos siguientes: Claudia Cascante de Rojas, "Ante el peligro de rendirle pleitesía a la literatura comunista en las aulas de nuestros colegios», La Nación, 18-X1-1958, p. 51, y Francisco Bello, «Relámpago», ídem, 30-IV-1971, p. 15. 
El taller es otro texto de Carlos Luis Fallas originado en páginas periodísticas. En efecto, antes de su publicación literaria, el relato apareció por entregas en el semanario Adelante.

Independientemente de su carácter literario, $E l$ taller tiene un gran interés documental. En él Fallas se propone mostrar un medio y un tiempo que también conoció muy bien. Se trata del ambiente obrero costarricense de los años treinta, en particular el de los zapateros, y los primeros años de lucha de su partido en el campo sindical.

\section{IV}

En sentido estricto, la actividad literaria de Carlos Luis Fallas abarca un período aproximado de unos doce años. Su trabajo de escritor comienza a la altura de los treinta y un años de edad y declina al acercarse a los cuarenta y dos. Por otra parte, si hacemos caso a las fechas que aparecen al final de los textos, resulta que el orden de publicación de las obras de Fallas es algo diferente al de su composición. Mi madrina está fechada por el autor en 1950. Barreteros, por su parte, se inscribe en la época de Mamita Yunai, puesto que el autor la firma en 1941.

De acuerdo con lo anterior, Marcos Ramirez sería la última novela escrita por Fallas, quien la fecha en 1951. A su vez, se observa que el trabajo del escritor se concentra en el período comprendido entre 1947 y 1951. En particular, llama la atención el año 1947, puesto que en él Fallas escribe no sólo Gentes y gentecillas, sino, además, otros textos que hoy no conocemos. Según consta en la "Autobiografía», en 1947 Fallas escribió otra novela y varias narraciones, pero desafortunadamente este material desapareció durante los acontecimientos posteriores a la Guerra Civil de $1948^{9}$. También sobresalen los años 1950 y 1951, puesto que durante ellos el autor escribe Mi madrina, El taller y Marcos Ramírez.

A la luz de los datos apuntados, puede afirmarse que el grueso de la producción literaria de Carlos Luis Fallas se da en los años quizá más vertiginosos de su vida política, es decir, los que antecedieron a la Guerra Civil de 1948 y el período inmediatamente posterior a esta fecha, que es justamente cuando su partido es declarado ilegal y desarrolla actividades clandestinas.

9 «En 1947 publiqué la novela Gentes y gentecillas, en una pésima edición que corregí luego pero que no he podido volver a editar. Ese mismo año escribí una novela y varios cuentos cortos que me fueron robados durante la represión de 1949.» Cfr. «Autobiografía» de la edición mexicana de Mamita Yunai en 1957. 
Varios testimonios coinciden en señalar que Fallas dejó inconclusos al menos dos libros. Uno de ellos, cuyo título iba a ser Rojo y verde, pretendía ser memoria de sus intervenciones políticas y de su actividad sindical. En el otro, que iba a llamarse Cartas a Juan, el autor deseaba recoger la correspondencia que mantuvo desde la Unión Soviética con un tío suyo.

Carlos Luis Fallas también había planeado otros escritos literarios, que, desafortunadamente, no llegó a realizar. Esto lo declara el mismo autor en un pasaje en que se destaca su posición autocrítica abierta y franca:

Se me quedó ese segundo tomo - se refiere a Mamita Yunai- en el tintero, como en el tintero se me han ido quedando también el segundo tomo de Marcos Ramírez y la continuación de El taller, incluido como novela corta en el libro Mi madrina, que apenas es la primera parte de una amplia novela sindical, etc. ¿Exceso de trabajo partidista, de diario trabajo revolucionario? No, vergonzosa desidia mía, injustificable incumplimiento de una muy importante tarea revolucionaria ${ }^{10}$.

Terminado el ciclo propiamente literario, se conocerán dos textos más del escritor. Ellos constituyen lo que podría llamarse su literatura ancilar.

En 1977, la Editorial de la Universidad de Costa Rica da a conocer Un mes en la China Roja, compilación de artículos escritos por Fallas en 1957 y que habían aparecido a lo largo de ese año en el período Adelante. En este libro, el autor narra diversos episodios de su viaje a China en 1956. El texto posee carácter de crónica y en él se conjugan intenciones políticas y didácticas, notas de humor cordial y un sostenido esfuerzo por comprender «desde dentro» una tradición cultural y una sociedad tan distantes a la experiencia del escritor. Al igual que en sus otros libros, Fallas exhibe aquí sensibilidad para el paisaje e interés por la descripción. La literatura actúa en él como medio para traer lo desconocido hacia lo familiar, y de este modo el autor acude al término aladinesco, por ejemplo, y se sirve de Las mil y una noches como punto de comparación.

Finalmente, en 1978 los Cuadernos Prometeo, de la Universidad Nacional, dedican su sexto número a Don Bárbaro. Este último texto es un documento de interés sociopolítico en que las resonancias novelescas del título apuntan, obviamente, al problema del agro. Originalmente había tenido difusión periodística en 1960.

10 Cfr. «Prólogo del autor para la edición cubana de Mamita Yunai». Este prólogo se reproduce en la misma obra al ser publicada en 1966 por la Editorial Principios de San José, Costa Rica. 
Las obras literarias de Carlos Luis Fallas figuran entre los textos costarricenses más difundidos en el plano internacional. Mamita Yunai ha sido traducida a unas diez lenguas - entre ellas el francés, el alemán, el chino y el ruso-, y en su idioma original ha conocido múltiples ediciones dentro del país y fuera de él. Aunque en menor grado, Marcos Ramirez también ha conocido una difusión similar. No obstante, por casi dos décadas o más la obra de Fallas tuvo en el país un cierto carácter marginal $\mathrm{y}$, de diversas formas, fue objeto de exclusión. Por eso, en algunos momentos la acogida internacional hizo contraste con el silencio o el rechazo locales.

Después de 1960 se advierte un proceso de creciente incorporación a la vida cultural del país, proceso que parece acentuarse después del fallecimiento del escritor.

A partir de 1980, la producción literaria de Carlos Luis Fallas conoce en su patria una difusión sin precedentes. Marcos Ramirez es convertida en texto fílmico por la televisora nacional, $y$, en una versión dramática, Mi madrina recorre el país en 1982.

En la actualidad, las referencias bibliográficas sobre Carlos Luis Fallas y su obra literaria son muy abundantes en Costa Rica. Sobre todo en los últimos tiempos se han acumulado los trabajos de diversos sectores académicos, tales como los de la filología y la historia. Sin embargo, no se han cotejado los enfoques ni se ha ponderado la resonancia heurística de los resultados obtenidos.

Un análisis de la crítica sobre Fallas alumbraría los presupuestos con que se han abordado las cuestiones $\mathrm{y}$, a la larga, introduciría la necesidad de nuevos temas y otras modalidades de reflexión. Esto podría verse notablemente enriquecido con aportaciones que ofrecen hoy los trabajos de las ciencias sociales.

La discusión crítica sobre los textos de Carlos Luis Fallas dista mucho de haberse agotado y, en cierta forma, quizá no se ha iniciado de manera cabal. Se impone hoy un balance, un momento de reflexión que ordene argumentos, destaque puntos de fuerza, elimine falsos problemas e ironice presiones oscurantistas de diversa procedencia.

La lectura de las obras de Fallas ha tendido a encerrarse en concepciones normativas de variada índole. Esto sólo puede originar una pseudocrítica de pose judicial, condenada a escoger en el marco de series binarias: protesta-conformidad, realismo-ficción, artificial-auténtico, buenomalo, etc. Es necesario abordar los textos más allá de este juego y pregun- 
tarnos, para empezar, lo que podríamos hacer con ellos. Las producciones literarias son un punto móvil en el campo de fuerzas de la escena social; no un lugar dado para siempre.

La mención de Fallas como escritor de tesis, de protesta y denuncia social es tópico obligado en todos los contextos. Sin embargo, estas afirmaciones han supuesto una recepción unívoca de las obras, idea que hace juego a la de una intención personal determinante. En otras palabras: el impacto social del texto de Fallas se ha considerado a la luz de modelos muy ingenuos de la circulación textual. Por eso su producción ha tendido a encerrarse en los marcos de una historia literaria de carácter acumulativo y lineal, una historia literaria sostenida en la idea de continuidad y evolución.

Para negarla o afirmarla, con el interés de atenuarla o subrayarla, la relación entre política y literatura constituye uno de los ejes fundamentales de los acercamientos a Fallas y su producción. No obstante, los planteamientos están muy viciados, puesto que no se manejan conceptos mínimos ni de la cuestión política ni de la literaria. Las afirmaciones parten de alternativas ya hechas y no de problemas que deben formularse o considerarse o de hipótesis que puedan discutirse. Obviamente, la producción literaria de Fallas constituye un punto de partida apropiado para el planteamiento de un tema que podría arrojar datos y direcciones de estudio quizá inéditas. En efecto, dadas las características y condiciones del «caso Fallas», quizá su actividad literaria resulte mucho más adecuada que otras para investigar la literatura costarricense en un ángulo todavía no explorado. Nos referimos a la articulación de lo político y lo literario.

Por lo demás, resulta curioso advertir que las discrepancias suscitadas por la actividad y la posición políticas de Fallas tienden a esfumarse a la hora de considerar sus textos. Partidarios de su línea social, enemigos de ella y neutrales coinciden en el mismo universo de pensamiento a la hora de la lectura literaria. Así, paradójicamente, un texto supuestamente ligado a las contradicciones sociales y derivado de ellas se convierte en la ocasión en que priva el consenso ideológico y desaparece la posibilidad del conflicto.

Entre los múltiples problemas que deben plantearse y replantearse en torno de la producción de Carlos Luis Fallas merece atención el de las bases naturalistas que se pueden advertir en su práctica literaria. ¿Por qué y cómo una gestión política orientada por el marxismo puede articularse con una escritura literaria de raíz positivista? Hay en este plano de estudio elementos muy interesantes no sólo para evaluar la actividad de Fallas y la circulación de sus textos, sino también para considerar muchos proyectos literarios en curso. Si bien es cierto que Mamita Yunai obliga a 
releer el costumbrismo, no por eso es menos cierto que la producción narrativa costarricense e hispanoamericana de los últimos años también nos impone reconsiderar la novelística de Fallas y, en general, de su período. Es decir, se hace necesario un examen de la novelística del autor en las coordenadas literarias y culturales de nuestros días. 
